\title{
Understanding Students' Motivation and Learning Strategies to Redesign Massive Open Online Courses based on Persuasive System Development
}

\author{
Mohamad Hidir Mhd Salim ${ }^{1}$, Nazlena Mohamad $\mathrm{Ali}^{2}$, Mohamad Taha Ijab ${ }^{3}$ \\ Institute of Visual Informatics, The National University of Malaysia \\ Bangi, Selangor, Malaysia
}

\begin{abstract}
Electronic learning or E-learning is currently flourishing immensely in areas such as secondary and tertiary education, lifelong learning programs and adult education. Within recent years, massive open online courses (MOOCs) have received profound attention within the field of E-learning. Persuasive principles can be implemented to enhance the system design and motivate students to engage with the system. The aim of this study is to identify students' motivation and learning strategies that affect their academic performance in using MOOCs among tertiary education students. 40 students enrolled in the Ethnic Relations course participated in the online survey. Motivated Strategies for Learning Questionnaire (MSLQ) is the instrument used in this study while Automatic Linear Modelling (ALM) and Multiple Linear Regression (MLR) were used in the analysis. The result shows that there is a correlation between students' motivation, learning strategies and their academic performance. It is found that resource management, cognitive and metacognitive and value component are the main scales that influenced their motivation and learning strategies towards excellent academic performance. The results can be used to fulfil the first phase of designing a persuasive system based on the Persuasive System Design (PSD) model which is to understand the issues behind a system.
\end{abstract}

Keywords-Persuasive; MOOCs; motivation; learning strategies

\section{INTRODUCTION}

Electronic learning or E-learning is currently flourishing immensely in areas such as secondary and tertiary education, lifelong learning programs and adult education [1]. Due to the advantages that E-learning brings to tertiary education institutions particularly the absence of reliance on the time requirements, the capacity to pose inquiries without timidity and access of materials from anyplace [2], the implementation of E-learning has become widely implemented [3]. E-learning is defined as the development of knowledge and skills using information and communication technologies (ICTs) to support interactions (i) with content, (ii) learning activities and tools, and (iii) other people. Internet learning, Web-based learning, and online learning are examples of E-Learning [4].

Massive open online courses (MOOCs) are online courses that developed for open, unlimited enrolment via the internet [5]. MOOCs are often released by third-party online platforms and developed independently by academics [6]. There are a few tertiary education institutions in Malaysia that have embarked on MOOCs initiative and they are currently at the implementation phase. These Malaysian universities are Universiti Putra Malaysia, Universiti Kebangsaan Malaysia, Universiti Malaysia Sarawak and Universiti Teknologi MARA. Malaysia's approach can be portrayed as exploratory. Hence, the implementation is focusing less on reaching the huge number of users or competing with established providers like edX, Udacity and Coursera, but more on educating the user to use web-based technology to complement current educational delivery systems at the higher education level as a way of familiarizing MOOCs to the general Malaysian audience [7]. There are four compulsory courses for Malaysia's undergraduate students namely Islamic and Asian Civilization, Ethnic Relations in Malaysia, Introduction to Entrepreneurship, and Information Communication Technology (ICT) Competency that use MOOCs as its learning platform [8].

There are issues regarding the use of MOOCs among tertiary students. These issues have to do with MOOCs themselves and their platforms, including learning engagement difficulty in MOOCs due to the limited of social presence, as well as lack of support and interaction in the platform [9]. Furthermore, learners lacking in learning strategies will not get much from open-ended learning [10] and it still uncertain on how MOOCs might affect students' motivations and participation, and how these later will impact their academic performance. By implementing persuasive technology, it might help solve these issues [11]. "Captology" (Computer as Persuasive Technology) or "persuasive technology" refers to a technology designed to influence users' behaviour without coercion [12]. This technology can be implemented in an e-learning system as assistance to improve students' behaviour [11] and elicit positive emotions in students using the persuasive principles according to the suitability to improve students' trust towards the system [13]. According to the persuasive system design (PSD) model, the development of persuasive systems involve three different phases: 1) understanding key issues behind the persuasive system, 2) analyzing the persuasion context, 3) designing the system qualities [14]. This paper will explain about the history of MOOCs, Persuasive System Development Model, Fogg Behaviour Model, and the instrument used in this study which is Motivated Strategies and Learning Questionnaire (MSLQ). This study aims to fulfil the first phase of persuasive system development by identifying students' motivation and learning 
strategies that can improve their academic performance. Understanding this relationship has important pedagogical and practical implications for future MOOC improvement [15].

\section{BACKGROUND STUDY}

We are currently at the beginning of the fourth industrial revolution (4IR). The industrial revolution commonly is a concept that changed the economy and society. Huge changes occurred within a short time. [16]. Tertiary education will also change significantly due to the impact of 4IR. [17]. This section reviews the history of MOOCs and the Malaysian universities efforts in implementing MOOCs, the persuasive system development process, the behaviour change model for persuasive design to give insight on how persuasive technology can affect behaviour and the instrument used to identify learning strategies and motivation factors.

\section{A. Massive Open Online Courses (MOOCs)}

The report State of the Field Review on E-learning argues that E-learning does not encompass a specific technology and can be used in hybrid approaches [4]. Research in the area of E-learning has demonstrated that the advantages offered by this environment are convenience and flexibility offered by the 'anytime and anywhere' accessibility [4]. Students can work at their own style of learning and this feature is crucial for a certain group of learners. However, some claim the webbased or online learning is not as effective as the traditional classroom because of it is lacking face to face interaction which caused learners felt disconnected from others due to lack of facial expression and other common features found in a traditional way of learning [18].

The development and implementation of e-learning have become a necessity for academic institutions. This is because of the benefits E-learning brings to universities [3]. To make this happen, technologies and innovations such as Massive Open Online Courses (MOOCs) are implemented. A few years back, MOOCs have become popular in the field of eLearning [19]. Although traditional online courses and MOOCs share commonalities because they are both offered online, both are different in terms of course structure and aims [20]. Unlike traditional online courses, MOOCs attract massive numbers of users and typically require little (or no) prior knowledge [21]. This kind of technologies will create greater dynamism and personalization of students' learning experience.

cMOOCs is the first phase of MOOCs development period in the comparatively short history of MOOCs. cMOOCs (the connectivist MOOCs) are based on "connectivist distributed peer learning model. Courses are typically developed and led by academics through open source web platforms" (Wulf, Blohm, \& Brenner, 2014, p. 6) [22]. xMOOCs is the second phase of MOOCs development. The xMOOCs period included online courses that are structured in a more conventional way and delivered through not simple web platforms but via some learning management platforms such as Coursera, EdX, Udacity, Udemy, Iversity, MiriadaX and Futurelearn. Some xMOOCs (content-based MOOCs) are also delivered through proprietary learning management platforms of institutions or individual academics [6].
There are five pillars in The National e-Learning Policy created by the Malaysian government which include curriculum and content, the structure of the organization, professional development and enculturation to enable Malaysia higher learning institutions to implement their initiatives towards e-learning. One of the benefits that MOOCs offer to Malaysian higher education system is by increasing students' enrolment and improve the quality of instruction at the same time to do all the necessary in a costefficient manner. The first of its kind in the world, these undergraduate courses bring together all first-year students from 20 Malaysian universities on a single platform. This launch is significant as it marks the first foray of Malaysian public universities into MOOCs [23].

MOOCs offer competence development and even certification. As a stand-alone solution, MOOCs offer chances for reflecting on and constructing new knowledge, but often they involve a minimum amount of live interaction. Many MOOCs continue to be online replications of classrooms primarily consisting of video lectures, multiple-choice quizzes, Q\&As and more informal after-class discussions in online discussion forums [24]. Students may have developed comprehension monitoring skills that imply when the material is insufficiently understood but may not use those skills if they are not having enough effort to really understand the contents. Understanding student learning, therefore, needs taking into consideration the dynamic exchange between cognition and motivation [25], [26].

\section{B. Persuasive System Development}

There are three phases in persuasive system development. Understanding the key issues behind the persuasive system is the first phase need to be taken. After getting a thorough understanding of the issues, the system can be analysed and designed by recognizing the intent, event and strategies for the use of persuasive systems. When those elements have been identified, the actual system qualities for a new system can be designed [27]. The first phase of the process is identified by getting significant learning strategies and motivation factors that affect students' academic performance.

Analyzing the persuasion context is the next phase in persuasive system development. It consists of three aspects which are the intent, the event and the strategy [27]. According to [28] there are three sources of intentions which are endogenous, exogenous, and autogenous. Endogenous belongs to people that produce interactive technology. While exogenous belongs to people that distribute or give the interactive technology access to others and autogenous belongs to people that adopting interactive technology. It is very important to determine these three sources of intention due to the reason that computers do not have intentions of their own [27]. The event involves understanding the situations around the behaviour to influence. There are three contexts that need to identify in the event including use context, user context and technological context. The use of context can be identified by understanding the features arising from the problem domain. While user context can be identified by focusing the end-user's individual differences which determine their level of technology literacy. Because of information technologies are expanding rapidly nowadays, 
identifying technological context is very crucial where the strength and weaknesses, along with the risk and opportunities of technological platforms need to be wholly recognised [27]. The strategy is the last aspect that needs to be identified in this phase. It is about the message that reaches the end-users. Having a proper message will increase the level of persuasion. Therefore, a deeper understanding of the message and how it works to persuade the end-users are important [29].

Design of system qualities is the last phase in persuasive system development. There are four categories in persuasive design principles which has been outlined by [30] in Persuasive System Design (PSD) model which are Primary Task Support, Dialogue Support, System Credibility Support and Social Support. Each category has its own design principles that need to be suitably selected to design an effective persuasive system. Primary task support consists of a set of principles that help simplify user's main task. While dialogue support is very useful to keep the end-users towards their target behaviour by implementing computer-human dialogue support. System credibility support explains about the way to design a credible persuasive system. Where the more credible a system is, the more persuasive it can be [27]. Lastly, the interaction between people through a computer has significant implication for persuasion [12]. To ensure that the end-users will remain motivated, social support will do the task by providing social interaction features between users. According to [31], there is proof that changing social norms would affect behaviour change.

\section{Behaviour Model}

There are some theories related to behaviours such as The Stage of Change Model and SNAP model. SNAP stands for "staying the old behaviour, new behaviour engagement, attempting to change and planning to change". Both theories describe the process of behaviour to occur. However, these theories are not explaining behaviour change [11]. This is because of a persuasive system is developed to influence users' behaviour. It is crucial to understand behaviour change model to ensure the system can deliver its purpose. Fogg Behaviour Model (FBM) explains a new way to understand factors that could give an impact on users' behaviour. The persuasive design could fail because of misunderstanding on these three021 factors which are motivation, ability and triggers. Users must have these three factors at the same time to ensure they perform the target behaviour [32]. Fig. 1 shows the visualization of The Fogg Behaviour Model. The figure shows that when users have high motivation, high ability with an appropriate type of triggers, it would be easy for users to perform the target behaviour.

Every factor in this model has its elements. Elements in motivation consist of pleasure/ pain, hope/ fear and social acceptance/ rejection. Pleasure/pain is a primitive response that functions adaptively in activities related to selfpreservation and the response is immediate. While the difference between hope and fear is the anticipation of good or bad situations that will happen if certain behaviours occur. Social acceptance/ rejection are elements that depend on users' surrounding because some users prefer to be socially accepted rather than socially rejected. Although users have high ability to perform a target behaviour, without having a certain level of motivation, the tendency for them not to reach the target behaviour is high [32].

The persuasive system must provide features that are simple to increase users' abilities to perform target behaviour. This factor has six elements, where every element is related. Those elements are time, money, physical effort, brain cycles, social deviance and non-routine. By considering users' time, the designer of a persuasive system will simplify the tasks given. For users that have limited financial resources, money would affect their ability to perform a target behaviour. The physical effort might not be simple for users who have problems with their health. Hence, this element should be considered before designing tasks for a persuasive system. While brain cycle is an element that requires users to think before they manage to complete a task. If the tasks are complicated, it will not persuade users to change behaviour. Social deviance means that if any tasks in the systems require users to against the norm, it is not simple for certain users. The last element in this factor is non-routine. Usually, users prefer to do tasks that can be performed in their routine unless they have enough motivation to do it. Users' abilities are different. Some users have money but do not have time. While some other users have time but cannot perform brain cycles activity and vice versa [32].

The last factor in the FBM model is triggers. Three types of triggers that contribute to behaviour change which are "spark", "facilitator" and "signal". The tendency for users to perform a target behaviour without enough motivation is low, even though they could do it. In this case, "spark" plays an important role to ensure users perform a target behaviour. "Spark" could be a video or a highlighted text that is designed to inspire users. "Facilitator" is a type of trigger for users who do not have the ability to perform target behaviour. The purpose of this type of trigger is to facilitate users to perform target behaviour while triggering them. It could be in a form of video, highlighted text, pictures and others. The last type of trigger is "signal". "Signal" is for users who have both motivation and ability. It works as a reminder for users and this type of trigger will not contribute to users' motivation or simplify tasks. All of these triggers are very useful to ensure users perform a target behaviour at the specific moment when users have both motivation and ability [32].

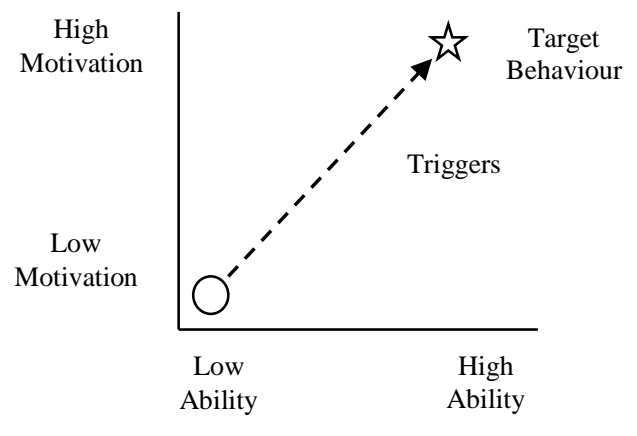

Fig. 1. The Fogg behaviour Model [32]. 


\section{Motivation Strategies and Learning Questionnaire} (MSLQ)

Two of the scales resulting from this previous work are the Learning and Study Strategies Index (LASSI) and the Motivated Strategies for Learning Questionnaire (MSLQ). One of the advantages of the MSLQ over LASSI is that there is no implied internal model that must be used to interpret results. The scales are also designed to be modular so as to allow a researcher to develop a model structure to fit the needs of a particular study [33]. This ability to customize the MSLQ makes it an appropriate choice for use in the present study as our research is of an exploratory in nature and therefore requires greater freedom in interpreting the data collected [11].

Table I shows the MSLQ components. The MSLQ consists of 81 items broadly categorized as part of either the motivation or learning strategies scales [33]. Those scales are divided into two levels of subscales and it comes together with the specific study behaviours. It is crucial to understand students' study behaviours before designing a persuasive system. Learning includes many different skills and abilities and so there are a lot of study behaviours that either has a positive or negative impact on learning performance. Previous research has thus sought to identify and categorize the types of study behaviours and strategies students typically have [34]. The MSLQ was developed using a social-cognitive view of motivation and learning strategies with the student represented as an active processor of information whose beliefs and cognitions mediated important instructional input and task characteristics [35].

TABLE. I. MOTIVATION STRATEGIES AND LEARNING QUESTIONNAIRE (MSLQ) COMPONENTS [33]

\begin{tabular}{|l|l|}
\hline Motivation Scales & Subscale \\
\hline \multirow{3}{*}{ Value } & Intrinsic Goal Orientation \\
\cline { 2 - 2 } & Extrinsic Goal Orientation \\
\cline { 2 - 2 } Expectancy & Task Value \\
\hline Affective & Control of Learning Beliefs \\
\cline { 2 - 2 } Learning Strategies Scales & Self-efficacy \\
\hline Scale & Test Anxiety \\
\hline \multirow{4}{*}{ Cognitive and Metacognitive } & Subscale \\
\cline { 2 - 2 } & Rehearsal \\
\cline { 2 - 2 } & Elaboration \\
\cline { 2 - 2 } & Organization \\
\cline { 2 - 2 } & Metacognitive Self-regulation \\
\hline \multirow{5}{*}{ Resource Management } & Time and Study Environment \\
\cline { 2 - 2 } & Effort Regulation \\
\cline { 2 - 2 } & Peer Learning \\
\cline { 2 - 2 } & Help-Seeking \\
\hline
\end{tabular}

\section{METHODOLOGY}

To identify students' motivation and learning strategies that affect their study behaviours, an online survey targeting students that were taking Ethnic Relations course using MOOCs was conducted. The online questionnaire is referred to as the MSLQ instrument with some modification. This part will explain every modification that has been made to the MSLQ instrument and the statistical approach used to analyze the results to determine the most factors that affect students' study behaviours.

The online questionnaire consists of four sections. The first and second sections are focusing on motivation and learning strategies for the students. These two sections have been going through some changes. Changes were made to the original form of the MSLQ questionnaire because the original MSLQ questionnaire was designed to be focused on the traditional ways of learning. This study focused on online learning. Hence, the generalization should be made to make it understandable and precise about the learning requirements. In order to address the issue, words related to traditional learning styles in MSLQ questionnaire like 'teacher' has been changed to "instructor", 'classroom' has been changed to "environment" and others have been changed according to the suitability of online learning.

The third section is about students' academic performance. This section is added because the original MSQL questionnaire did not ask about academic performance in which it is necessary for the researcher to do the assessment using their current performance in the course. These following questions were added to the questionnaire regarding students' academic performance:

1) What do you think about your academic performance as a student on this subject?

2) How frequently did you receive high grades (of over $80 \%$ ) for assignments, quizzes for this subject?

The last section consists of three open-ended questions, which are to identify students' opinion about the factors that affect their academic performance, their suggestions to improve current MOOCs system and the preferable features that they think can persuade students to use MOOCs system. Students had to answer all the questions using a 7-point Likert scale, which 1 indicates "not all true of me" and 7 indicates "very true of me" except for students' academic performance section which 1 indicates "poor" and 7 indicates "excellent" for the first question and for the second question, 1 indicates "never" and 7 indicates "often".

Forty (40) students who enrolled in Ethnic Relations course using the MOOCs system were the participants in this study. Ethnic Relations was chosen because the course is compulsory for every tertiary student in Malaysia. All forty participants are from Universiti Kebangsaan Malaysia and this experiment was not restricted to any years of study. To distribute the questionnaire, the web-based survey approached had been used which is Google Form. The process took about six weeks. The survey link was distributed through social media such as Facebook. To reach the exact group of students, the link had been shared in a specific Facebook group which is 
related to the course. Facebook was selected because it is a popular choice among the students and lecturers to communicate and sharing things regarding academic matters. Other than that, the link also had been shared using WhatsApp messaging application to increase the potential for reaching the students to answer the questionnaire. This platform was aiming at students who do not have Facebook accounts.

SPSS software was used to analyze the data. Automatic Linear Modelling (ALM) and Multiple Linear Regression (MLR) were the statistical analysis that had been applied to narrowing the students' motivation and learning strategies according to the MSLQ questionnaire. ALM was used to rank the list of variables and their impact factors. We chose academic performance as the dependent variable and all the MSLQ items as independent variables. Top ten variables with the largest impact factors had been considered as significant. To form an equation, the top ten variables selected from ALM had gone through the MLR process. The variables that did not fall below 0.5 significance were excluded. This process stops until significant variables appeared within the Durbin-Watson value range between 1 and 3 [36].

\section{RESULTS AND DISCUSSION}

In this part, the findings in terms of students' demographic (Section 1), motivation (Section 2), learning strategies (Section 3) and their opinions about the current MOOC system (Section 4) are reported. All of them have experienced using the MOOCs system specifically in the Ethnic Relations course.

As Table II summarizes, this study involved $45 \%$ of male and $55 \%$ of female students. $20 \%$ of them are from Art \& Humanities discipline and $80 \%$ of them are from the Science $\&$ Technology discipline. Most of them were second-year students which consisted of $47.5 \%$ of students, $32.5 \%$ of them were third-year students and $20 \%$ of them were fourth-year students. $72.5 \%$ of students involved in this study were taking more than five subjects and $22.5 \%$ of them were taking two to five subjects during the current term. Most of them took about one to ten hours a week to study which consisted of $80 \%$ of students and only $20 \%$ of students took about 10 to 30 hours a week to study for the course.

Table III displays the students' academic performance. Most of them described that their academic performance was at a good level. $75 \%$ of students chose 5 to 6 which indicate that they performed well in their academic. $20 \%$ of them chose 4 which is neutral and only $5 \%$ of them chose 3 and 2 which imply that they have nearly poor academic performance. Almost half of the students which is $67.5 \%$ of students that involved in this study stated that they often received high grades for assignment, quizzes for the subject and $27.5 \%$ of students chose neutral in response to the statement and only $5 \%$ of students chose 3 to 1 . From all the data above, most of the students involved in this study are well-performed students which received a grade of above $80 \%$ and can be categorized as students that have a real understanding on the subject [37]. This is indicating that good students incline to answer a survey compared to students that have poor academic performance. Since most of the students participated in this study are well-performing students, the data collected are inclined towards only one group of students.
But the result is still valid to test whether there is a correlation between students' motivation, learning strategies and their good academic performance.

Table IV shows the reliability results for the model. $88.2 \%$ ALM accuracy and the Durbin-Watson values were in an acceptable range of 1 to 3 , shows that the model satisfies the reliability criteria. An explanation of the model is presented below.

$\mathrm{f}(\mathrm{x})=(0.554) \mathrm{x} 1+(0.364) \mathrm{x} 2+(-0.325) \times 3+(0.212) \times 4+(-$

$0.229) \times 5+(0.196) \times 6+1.18$

TABLE. II. DEMOGRAPHIC INFORMATION

\begin{tabular}{|c|c|c|c|}
\hline Items & Statements & Response & $(\mathrm{n}=40) \%$ \\
\hline \multirow{2}{*}{1.} & \multirow{2}{*}{ Gender } & Male & $18(45 \%)$ \\
\hline & & Female & $22(55 \%)$ \\
\hline \multirow{2}{*}{2.} & \multirow{2}{*}{$\begin{array}{l}\text { What discipline you } \\
\text { are in your study? }\end{array}$} & Art \& Humanities & $8(20 \%)$ \\
\hline & & Science \& Technology & $32(80 \%)$ \\
\hline \multirow{3}{*}{3.} & \multirow{3}{*}{$\begin{array}{l}\text { What year you are } \\
\text { now in tertiary } \\
\text { education? }\end{array}$} & 2nd Year & $19(47.5 \%)$ \\
\hline & & 3rd Year & $13(32.5 \%)$ \\
\hline & & 4th Year & $8(20 \%)$ \\
\hline \multirow{5}{*}{4.} & \multirow{5}{*}{$\begin{array}{l}\text { How many subjects } \\
\text { are you taking this } \\
\text { term? }\end{array}$} & 2 subjects & $3(7.5 \%)$ \\
\hline & & 3 subjects & 0 \\
\hline & & 4 subjects & $1(2.5 \%)$ \\
\hline & & 5 subjects & $5(12.5 \%)$ \\
\hline & & More than 5 subjects & $29(72.5 \%)$ \\
\hline \multirow{4}{*}{5.} & \multirow{4}{*}{$\begin{array}{l}\text { How many hours a } \\
\text { week do you study } \\
\text { for this course? }\end{array}$} & 1 to 10 hours & $32(80 \%)$ \\
\hline & & 10 to 20 hours & $1(2.5 \%)$ \\
\hline & & 20 to 30 hours & $7(17.5 \%)$ \\
\hline & & 30 hours and above & 0 \\
\hline
\end{tabular}

TABLE. III. StUdents' ACADEMIC Performance

\begin{tabular}{|c|c|c|c|}
\hline Items & Statements & Response & $(\mathrm{n}=40) \%$ \\
\hline \multirow{7}{*}{1.} & \multirow{7}{*}{$\begin{array}{l}\text { What do you think about your } \\
\text { academic performance as a student } \\
\text { for this subject? }\end{array}$} & 1 (Poor) & 0 \\
\hline & & 2 & $1(2.5 \%)$ \\
\hline & & 3 & $1(2.5 \%)$ \\
\hline & & 4 & $8(20 \%)$ \\
\hline & & 5 & $18(45 \%)$ \\
\hline & & 6 & $8(20 \%)$ \\
\hline & & 7 (Excellent) & $4(10 \%)$ \\
\hline \multirow{7}{*}{2.} & \multirow{7}{*}{$\begin{array}{l}\text { How frequently did you receive high } \\
\text { grades (of over } 80 \% \text { ) for } \\
\text { assignments, quizzes for this subject? }\end{array}$} & 1 (Never) & 0 \\
\hline & & 2 & $1(2.5 \%)$ \\
\hline & & 3 & $1(2.5 \%)$ \\
\hline & & 4 & $\begin{array}{l}11 \\
(27.5 \%)\end{array}$ \\
\hline & & 5 & $\begin{array}{l}15 \\
(37.5 \%) \\
\end{array}$ \\
\hline & & 6 & $8(20 \%)$ \\
\hline & & 7 (Often) & $4(10 \%)$ \\
\hline
\end{tabular}

TABLE. IV. RELIABILITY RESULTS

\begin{tabular}{|l|l|l|l|}
\hline & ALM Accuracy & Durbin-Watson & $\mathrm{r} 2$ \\
\hline Overall model & $88.2 \%$ & 1.815 & 0.882 \\
\hline
\end{tabular}


Where $f(x)=$ How would you describe your academic performance as a student? $\mathrm{x} 1$ = I make sure that I keep up with the weekly readings and assignments for this course, $\mathrm{x} 2=\mathrm{I}$ $\log$ in to the system regularly, $\mathrm{x} 3=\mathrm{I}$ try to think through a topic and decide what I am supposed to learn from it rather than just reading it over when studying for this course, $\mathrm{x} 4=\mathrm{I}$ rarely find time to review my notes or readings before an exam (reversed), x5 $=$ Whenever I read or hear an assertion or conclusion in this course, I think about possible alternatives, x6 = If I can, I want to get better grades in this course than most of the other students.

Based on Table $\mathrm{V}$, it shows that there are six study behaviours represent students' motivation and learning strategies that affect academic performance. Based on the MSLQ questionnaire, every statement has its scale and subscale that related to students' study behaviours. These study behaviours will be considered as target behaviours as the first step to redesign MOOCs based on persuasive system development.

Study behaviour $1(x 1)$ specifies that students with good academic performances will ensure that they keep up with the weekly readings and assignments for the course they are taken. Good students will prepare themselves before the learning process started. This could be one of the factors that lead to excellent performance in academic. According to the study results, most of them are well-performed students. Hence, we could say that they do not face motivational and ability issues. To encourage this category of students to keep up with the weekly readings, factors such as triggers should be considered. "signal" is the type of trigger that could help students to perform study behaviour $1(x l)$ by reminding them if a new material uploaded by instructors.

Study behaviour $2(x 2)$ shows that students who login to the system (MOOCs) frequently will have the potential to perform better than other students who seldom log in to the system. Therefore, the appropriate reason to log in the system should be highlighted as a motivation factor. Reasons like getting news about assignments, quizzes or any new materials uploaded by the instructors could encourage students to frequently login to the system as well as improving their academic performance. "Spark" and "signal" also can trigger students to perform the behaviour.

Metacognitive self-regulation is the subscale that we use to represent students that try to think through a topic and decide what they are supposed to learn rather than just reading it over when study for the course just like study behaviour 3 (x3). This kind of study behaviour may also lead to good academic performance. To let them perform this behaviour, the system should suggest related sources and trigger them by giving a signal with an appropriate message. It will save their time and decrease the brain cycle of the students. However, decreasing students' brain cycle would discourage students to think critically. Hence, instructors should plan the tasks by considering the critical thinking aspect of the students.

Students who may not have time to review the notes given by the instructors before an exam will have a difficult time to score in their exams. It shows in study behaviour $4(x 4)$. To overcome this issue, the system should emphasize the importance of reviewing notes before an exam by considering "hope/fear" element by reminding them to review the notes provided by the instructors. Other than that, the system should provide simplified features to ensure the system is easy to use while saving students' time to access and review notes. In other words, the efficiency of the system should be increased to ensure the students can perform the behaviour.

Critical thinking is another subscale that characterizes students who try to think possible alternatives, whenever they found an assertion or conclusion. Critical thinking is a crucial process, especially for tertiary students. It teaches them to complete problem-solving assessments. Study behaviour 5 (x5) belongs to the critical thinking subscale that would encourage students to have a good score in their academic. Because of the critical thinking process requires students to deeply think, it would decrease the students' motivation to perform the behaviour. Hence, to overcome this issue, the system should optimize the elements of simplicity and implementing suitable types of triggers such as "spark" and "facilitator" to let them focus on the task without facing any unnecessary problems.

The last study behaviour that will increase students' academic performance is when they try to compete with their friends to get better grades $(x 6)$. Social deviance is one of the elements in the Fogg Behaviour Model (FBM) that falls under the "ability" factor. If getting a good grade is a norm for students, it will boost their spirit to give extra effort and perform well in their academic. Therefore, the system should motivate students by giving them hope to perform the behaviour and consistently trigger them with positive messages.

TABLE. V. RELATED MSLQ SCALES AND SUBSCALES

\begin{tabular}{|c|c|c|c|}
\hline Equation & Study Behavior & Scale & Subscale \\
\hline $\mathrm{x} 1$ & $\begin{array}{l}\text { I make sure that I keep } \\
\text { up with the weekly } \\
\text { readings and } \\
\text { assignments for this } \\
\text { course }\end{array}$ & $\begin{array}{l}\text { Resource } \\
\text { Management } \\
\text { Strategies (Learning } \\
\text { Strategies) }\end{array}$ & $\begin{array}{l}\text { Time and } \\
\text { Study } \\
\text { Environment }\end{array}$ \\
\hline $\mathrm{x} 2$ & $\begin{array}{l}\text { I log in to the system } \\
\text { regularly }\end{array}$ & $\begin{array}{l}\text { Resource } \\
\text { Management } \\
\text { Strategies (Learning } \\
\text { Strategies) }\end{array}$ & $\begin{array}{l}\text { Time and } \\
\text { Study } \\
\text { Environment }\end{array}$ \\
\hline $\mathrm{x} 3$ & $\begin{array}{l}\text { I try to think through a } \\
\text { topic and decide what I } \\
\text { am supposed to learn } \\
\text { from it rather than just } \\
\text { reading it over when } \\
\text { studying for this course }\end{array}$ & $\begin{array}{l}\text { Cognitive and } \\
\text { Metacognitive } \\
\text { Strategies } \\
\text { (Learning Strategies) }\end{array}$ & $\begin{array}{l}\text { Metacognitive } \\
\text { Self-Regulation }\end{array}$ \\
\hline $\mathrm{x} 4$ & $\begin{array}{l}\text { I rarely find time to } \\
\text { review my notes or } \\
\text { readings before an exam } \\
\text { (reversed) }\end{array}$ & $\begin{array}{l}\text { Resource } \\
\text { Management } \\
\text { Strategies (Learning } \\
\text { Strategies) }\end{array}$ & $\begin{array}{l}\text { Time and } \\
\text { Study } \\
\text { Environment }\end{array}$ \\
\hline $\mathrm{x} 5$ & $\begin{array}{l}\text { Whenever I read or hear } \\
\text { an assertion or } \\
\text { conclusion in this } \\
\text { course, I think about } \\
\text { possible alternatives }\end{array}$ & $\begin{array}{l}\text { Cognitive and } \\
\text { Metacognitive } \\
\text { Strategies (Learning } \\
\text { Strategies) }\end{array}$ & $\begin{array}{l}\text { Critical } \\
\text { Thinking }\end{array}$ \\
\hline x6 & $\begin{array}{l}\text { If I can, I want to get } \\
\text { better grades in this } \\
\text { course than most of the } \\
\text { other students }\end{array}$ & $\begin{array}{l}\text { Value } \\
\text { Component } \\
\text { (Motivation) }\end{array}$ & $\begin{array}{l}\text { Extrinsic Goal } \\
\text { Orientation }\end{array}$ \\
\hline
\end{tabular}


The last section in the questionnaire asks the students about their opinions on the existing MOOC. Time management and motivation are two popular answers given by the students in this study to become the factors that affect their academic performance. These two answers indicate that time and study environment plays an important role in their learning process. When they can manage their time effectively, they tend to be successful in their academic. Furthermore, when they surround themselves with positive people, it will encourage them not to waste their time. There are some suggestions to improve the existing MOOC. As one of the students wrote that "give notification through email if the deadline of a task is near the corner" shows that positive trigger gives an impact to their study behaviour. A statement like "easily access using a smartphone" indicates that there are students who prefer to learn using a mobile application instead of the web system. Other than that, students also want to have extra features like animated user interface and live chat. These features will let them communicate with their instructor and friends easily. They also suggest putting some gamification elements to make the application seems interesting to the students. It will also attract the students to $\log$ in to the system frequently. All the above statements are the popular statements given by the students in this section. It signifies that students are interested to learn through MOOC but there are some improvements that still can be made to the existing system to expand students' potential.

\section{CONCLUSION AND IMPLICATIONS}

The result concludes that there are six study behaviours that significant to be the factors that affect students' academic performance using MOOCs in Ethnic Relations course. All these study behaviours can be used as target behaviours to redesign MOOCs according to the Persuasive System Design (PSD) model. The study also fulfils the first phase of designing a successful persuasive system which is understanding the key issues behind a persuasive system. Five study behaviours represent learning strategies and only one study behaviour represents motivation. Time and study environment is the subscale which affecting students' academic performance the most. It signifies that students must be able to manage and regulate their time and study environments. Scheduling, planning, and managing are time management routines that should be applied by students. Metacognition self-regulation consists of three general processes which are planning, monitoring, and regulating. It assists students to apply their prior knowledge to understand the subject material before the learning process even begins. Students' critical thinking can be tested by letting them apply their previous knowledge to solve a problem. Reasons such as grades, rewards, performance, evaluation by others would be the factors to encourage students to score in their subjects. This subscale refers to the general orientation of the course.

This study has implications for instructors and system developers of MOOCs. Study behaviours that found in this study can give an insight for instructors on how students can improve their academic performance in MOOCs. By understanding the relationships between study behaviours and how it affects students' academic performance, instructors will be able to develop their contents for future MOOCs and influence students to perform better. However, the roles of instructors are limited to only prepare contents and utilize the existing system's features. Instead of instructors, the study results also contribute insight to system developers. By understanding the study behaviours that represent students' motivation and learning strategies which could affect academic performance, system developers can use the resulted study behaviours to redesign the system's features that able to empower students to improve their academic performance and increase the effectiveness of the system.

\section{LIMITATIONS AND FUTURE DiRECTIONS}

Despite the constructed model that has been produced in this study, there are few limitations of the research identified. The sample size was considered small. Even though it was enough to compute the statistical analysis, the model produced was restricted according to only a group of students. A variety group of students in different subjects should be involved in the future study to get a more holistic model because students' academic performance also relied on the subjects they took in their previous semester. To get an in-depth understanding of the students' motivation and learning strategies, students that received poor academic result also need to be involved. A comparison can be made between these two types of students to identify the factors that are still lacking in the current MOOCs system. This comparison study is indispensable to ensure that every level of students can get benefit from the system. MOOCs is a technology concept that is very useful for tertiary education students. But still, it needs some improvements to increase the persuasiveness of the system. In addition, to improve the system, students also need to change their study behaviour to excel in their academic. Technology is just a tool to ease the learning processes. Instructors and students should try to create teaching and learning outcomes. On the other hand, instructors including lecturers and teachers are the one who must have an in-depth understanding of their content and pedagogical aspects.

\section{REFERENCES}

[1] H. Kimiloglu, M. Ozturan, and B. Kutlu, "Perceptions About and Attitude Toward the Usage of E-Learning in Corporate Training," Comput. Human Behav., vol. 72, pp. 339-349, 2017.

[2] J. A. Rudy, "EDUCAUSE Core Data Service. 2009," Summ. Rep., 2007.

[3] W. M. Al-rahmi, M. S. Othman, and L. Mi Yusuf, "The Effectiveness of Using E-Learning in Malaysian Higher Education: A Case Study Universiti Teknologi Malaysia," Mediterr. J. Soc. Sci., vol. 6, no. 5, pp. 625-637, 2015.

[4] S. Folinsbee, "Online Learning for Adults: Factors That Contribute to Success," 2008.

[5] A. M. Kaplan and M. Haenlein, "Higher education and the digital revolution: About MOOCs, SPOCs, social media, and the Cookie Monster," Bus. Horiz., vol. 59, no. 4, pp. 441-450, 2016.

[6] M. H. Baturay, "An Overview of the World of MOOCs," Procedia Soc. Behav. Sci., vol. 174, pp. 427-433, 2015.

[7] M. Fadzil, L. Abdol, L. Tengku, and A. Munira, "MOOCs in Malaysia: A Preliminary Case Study," E-ASEM Forum Renewing Lifelong Learn. Agenda Futur., pp. 1-17, 2016.

[8] Prime Minister's Department, "Transforming Education System," 2016.

[9] X. Wang, A. H. Hall, and Q. Wang, "Investigating the implementation of accredited massive online open courses (MOOCs) in higher education: The boon and the bane," Australas. J. Educ. Technol., vol. 35, no. September 2013, pp. 1-14, 2018. 
[10] R. Azevedo, "Using Hypermedia as a Metacognitive Tool for Enhancing Student Learning? The Role of Self- Regulated Learning," Educ. Psychol., no. October 2014, pp. 199-209, 2005.

[11] J. Filippou, C. Cheong, and F. Cheong, "Modelling the Impact of Study Behaviours on Academic Performance to Inform the Design of a Persuasive System," Inf. Manag., vol. 53, no. 7, pp. 892-903, 2016.

[12] B. J. Fogg, Persuasive Technology: Using Computers to Change What We Think and Do. 2003.

[13] W. N. W. Ahmad and N. M. Ali, "A Study on Persuasive Technologies: The Relationship between User Emotions, Trust and Persuasion," Int. J. Interact. Multimed. Artif. Intell., vol. inPress, no. inPress, p. 1, 2018.

[14] H. Oinas-kukkonen and M. Harjumaa, "Persuasive Systems Design: Key Issues , Process Model , and System Features," Commun. Assoc. Inf. Syst., vol. 24, no. 28, pp. 485-500, 2009.

[15] P. De Barba, J. Lodge, G. Kennedy, L. Corrin, and A. Brooker, "A tale of two MOOCs: How student motivation and participation predict learning outcomes in different MOOCs," Australas. J. Educ. Technol., vol. 34, no. 1, pp. 73-87, 2017.

[16] J. Bloem, M. Van Doorn, S. Duivestein, D. Excoffier, R. Maas, and E. Van Ommeren, "The Fourth Industrial Revolution Things to Tighten the Link Between it and ot," 2014.

[17] N. W. Gleason, Higher Education in the Era of the Fourth Industrial Revolution. 2018.

[18] M. Sohn and J. Lee, "UP health: Ubiquitously Persuasive Health Promotion with an Instant Messaging System," 25th SIGCHI Conf. Hum. Factors Comput. Syst. 2007, CHI 2007, pp. 2663-2668, 2007.

[19] S. S. Noesgaard, R. Ørngreen, S. Schack, and K. Foundation, "The Effectiveness of E-Learning: An Explorative and Integrative Review of the Definitions, Methodologies and Factors that Promote e-Learning Effectiveness," Electron. J. e-Learning, vol. 13, no. 4, pp. 278-290, 2015.

[20] L. W. Perna et al., "Moving Through MOOCs: Understanding the Progression of Users in Massive Open Online Courses," Educ. Res., vol. 43, no. 9, pp. 421-432, 2014.

[21] B. K. Pursel, L. Zhang, K. W. Jablokow, G. W. Choi, and D. Velegol, "Understanding MOOC students: Motivations and behaviours indicative of MOOC completion," J. Comput. Assist. Learn., vol. 32, no. 3, pp. 202-217, 2016.

[22] J. Wulf, I. Blohm, and W. Brenner, "Massive open online courses: Higher Education's Digital Moment?,” Bus. Inf. Syst. Eng., vol. 6, no. 2, pp. 111-114, 2014.

[23] Ministry of Education Malaysia (MoE), "Malaysia Education Blueprint 2015-2025 (Higher Education)," Minist. Educ. Malaysia, vol. 2025, p. 40, 2015.
[24] S. Schack and K. Foundation, "The Effectiveness of E-Learning: An Explorative and Integrative Review of the Definitions, Methodologies and Factors that Promote e-Learning Effectiveness," Electron. J. eLearning, vol. 13, no. 4, pp. 278-290, 2015.

[25] P. R. Pintrich and B. Schrauben, "Students' motivational beliefs and their cognitive engagement in classroom academic tasks," in Student perceptions in the classroom, 1992, pp. 149-183.

[26] P. R. Pintrich, "The dynamic interplay of student motivation and cognition in the college classroom.," in Advances in motivation and achievement: Vol. 6. Motivation enhancing environments, 1989, pp. 117-160.

[27] H. Oinas-kukkonen and M. Harjumaa, "Communications of the Association for Information Systems Persuasive Systems Design: Key Issues, Process Model, and System Features Persuasive Systems Design : Key Issues, Process Model, and System Features," Commun. Assoc. Inf. Syst., vol. 24, no. 28, pp. 485-500, 2009.

[28] B. J. Fogg, "Persuasive computers: perspectives and research directions," in Analysis, 1998.

[29] J. Filippou, C. Cheong, and F. Cheong, "Combining the Fogg Behavioural Model and Hook Model To Design Features in a Persuasive App To Improve Study Habits,” Australas. Conf. Inf. Syst., 2015.

[30] H. Oinas-Kukkonen and M. Harjumaa, "A Systematic Framework for Designing and Evaluating Persuasive Systems," Persuas. Technol. Third Int. Conf. Persuas. 2008, Oulu, Finland, June 4-6, 2008. Proc., pp. 164176, 2008.

[31] B. Dohnke, E. Weiss-Gerlach, and C. D. Spies, "Social influences on the motivation to quit smoking: Main and moderating effects of social norms," Addict. Behav., 2011.

[32] B. Fogg, "A Behavior Model for Persuasive Design," 2009.

[33] P. R. Pintrich, D. A. F. Smith, T. Garcia, and W. J. McKeachie, "A Manual for the Use of the Motivated Strategies for Learning Questionnare," no. August, pp. 4-75, 1991.

[34] E. D. Fitkov-Norris and A. Yeghiazarian, "Measuring study habits in higher education: The way forward?,” J. Phys. Conf. Ser., vol. 459, no. $1,2013$.

[35] T. G. Duncan and W. J. Mckeachie, "The Making of the Motivated Strategies for Learning Questionnaire," Educ. Psychol., vol. 40, no. 2, pp. 117-128, 2005.

[36] A. Field, J. Miles, and Z. Field, Discovering Statistics Using SPSS, vol. 81, no. 1. 2013.

[37] J. H. Block and R. B. Burns, "1: Mastery Learning," Rev. Res. Educ., vol. 4, no. 1, pp. 3-49, 1976. 